\title{
A STUDY ON CORRELATION BETWEEN MORPHOMETRY OF CYSTIC DUCT AND CYSTIC ARTERY.
}

\section{Shilpa}

\section{Dr. Dhiraj Saxena*}

Shabina
PhD Scholar, SMS Medical college \& Hospital, Jaipur. Senior Professor SMS Medical college \& Hospital, Jaipur. *Corresponding Author $\mathrm{PhD}$ Scholar, SMS Medical college \& Hospital, Jaipur.

ABSTRACT Cystic artery and Cystic duct both are related to Calot's Triangle, which is one of the most frequently operated regions. Aim of Study to find if any correlation exists between Cystic artery and cystic duct in term of length, width and other variations. Study was conducted on 60 Cadaver in department of Anatomy SMS Medical College and hospital, Jaipur (Raj). Ethical clearance was taken from ethical committee of the institute. Photographs were taken where necessary. Variations in Cystic artery were frequent than the CD. Significant correlation was found between variations of CA \& CD. Recognition of Close association of $C A \& C D$ is necessary for surgeons as these structures are part of Calot's triangle.

\section{KEYWORDS : Cystic artery, Cystic Duct, Variations}

\section{INTRODUCTION}

Cystic artery (CA) is main arterial source for Gallbladder and associated structures. It arises from Right hepatic artery in the Calot's triangle usually. CA is most commonly structure to be damaged during surgical procedure in the Hepatobiliary area if its variations are ignored.

In the Calot's triangle it is closely related to the cystic duct (CD). CD is related to GB proximally and CHD distally. It often follow spiral course, variations are quite common in the insertion and course are also. A surgeon must be aware of these relations and variation to avoid chronic and fatal complications as this is most commonly operated area.

Relation of CA with CD must keep in mind because so many complications can occurs if theses variation ignored during cholecystectomy.

Aim of this study was to identify correlation between length, diameter and other variation of $C A$ and $C D$.

\section{MATERIAL \& METHOD:}

The study was conducted on 60 cadaver in the department of anatomy S.M.S.Medical College and hospital, Jaipur (Raj).Anterior abdominal wall was opened and peritoneum reflected carefully.CA and CD were exposed and surrounding structures were cleaned to see relation and variations of these structures. Length and diameter was taken using measuring scale and Vernier caliper. Photographs were taken where necessary. Statistical analysis was done using SPSS 20.ethical permission was taken from the concerned committee of the institute

\section{RESULT:}

1. Average length of CD was $23.18 \mathrm{~mm}$ with diameter of $4.75 \mathrm{~mm}$.

2. Average length of $\mathrm{CA}$ was $23.85 \mathrm{~mm}$ with diameter of $2.01 \mathrm{~mm}$.

3. Significant correlation was found between length of $\mathrm{CA}$ and CD.

4. Highly significant correlation was found between diameter of $C A$ and $C D$.

5. CA and CD were normal in 29 cadaver

6. Variation for both structures found in 7 Cadaver.

7. CA variation without CD variation was found in 24 Cadaver whereas CD variation alone was found in 8 cadaver.

8. In term of course CA was superomedial to $C D$ in 15 cadaver. Inferior relation was found in 2 cadaver, anterior relation was found in 10 cadaver whereas there was no relation in 26 cadaver between $\mathrm{CA} \& \mathrm{CD}$.

9. CA was related to both surfaces of $C D$ in 7 subjects. These cadaver had Double Cystic artery

10. Posterior relation was not found.

\section{DISCUSSION}

Relationship of CA \& CD is crucial during cholecystectomy. Wide variety of variations has been seen in this aspect as both are related to Calot's Triangle.

Length of CD ranged between 7-47 mm with Average length of CD was $(23.2 \mathrm{~mm})$ similar documented by Dandekar et al. ${ }^{(1)}$ Short CD $(7 \mathrm{~mm})$ was observed in $1.33 \%$ cases in present study. Short CD may get damage due to traction in this area while performing invasive procedure.

Average length of CA was observed $23.85 \mathrm{~mm}$ (range $4-52 \mathrm{~mm}$ ) in present study which is similar to reported by Marniok et al. ${ }^{(2)}$ Incidence of short $C A(<1)$ was found in $6.67 \%$ cadaver which is similar Taimur et $\mathrm{l}^{(3)}$

Significant correlation was found between length of CA and CD.

Diameter of CD was more in present study than previously reported literature. ${ }^{[2]}$ Average diameter was $4.73 \mathrm{~mm}$ in present study. This is in agreement with Turner et al ${ }^{(4)}$ Average diameter of $\mathrm{CA}$ was observed $2 \mathrm{~mm}$ which is in agreement with documented by R. Ramakrishna et al. ${ }^{(5)}$

Highly significant correlation was found between diameter of CD and CA. $(p<.05)$

According to prevalence of variation cadaver were divided into four categories were made:

No variation- Cadaver with normal anatomy of $C A$ and $C D$ were included in this category.

Variation in CA and CD both-In this category variation was found in Cystic artery and Cystic duct both.

Variation in CA only-in this category cystic artery variant were found, No CD variant was present in these cadavers.

Variation in CD only- Cadaver with only Cystic duct variant were included in the category.

CA variant were found in $40 \%$ cases .CD variant were present in $25 \%$ cases. Significant association was found between variant of $C A$ and $C D$. 
Cystic artery was superomedial to CD in $25 \%$ subjects. There was no relation between $\mathrm{CA}$ and $\mathrm{CD}$ in $43.34 \%$ cases.

In $3.34 \%$ cases where DCA was present both arteries were encircling the CD. (figl) These two arteries were superficial and deep branches of CA as its main trunk divides initially.

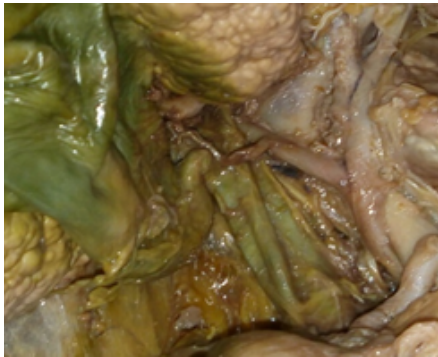

Fig 1. Superficial And Deep Br Encircling The CD

In other $6.67 \%$ cases of DCA one artery was anterior and other was posterior to Cystic duct.(fig.2)

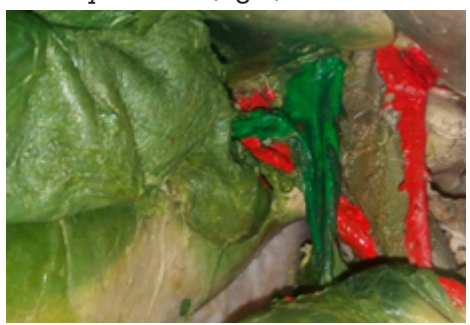

Fig.2: DCA Passing Anterior And Posterior To CD

It was inferior in $3.34 \%$ cases in present study. These case were of presence of DCA in which on e artery was present inside the Calot's triangle and other artery approaching the GB from other source of origin.(fig3)

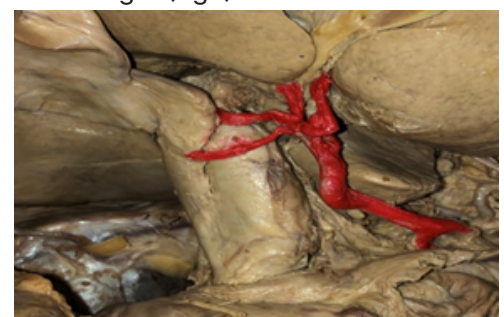

Fig.3: CA related to anterior and posterior both aspects of CD

Suzaki et al [6] found inferior position of $C A$ in relation with $C D$ in $6 \%$ cases. Inferior position of CA can be misinterpreted for absence of CA as it is not present in the Calot's Triangle.

CA was related anterior to CD in $16.67 \%$ cases in the study. (fig4) Similar observation was done by Doherty [7] in 15\% cases. The cystic artery was noted to be passing anterior to the cystic duct in 10\% cases by Gawali et al [8]. Higher incidence of anterior relation of $\mathrm{CA}$ was reported by Dundareddy et al [9] in $45 \%$ cases. Anterior position of CA is dangerous as it is first structure to reveal during cholecystectomy so surgeon must be careful for this kind of variation.

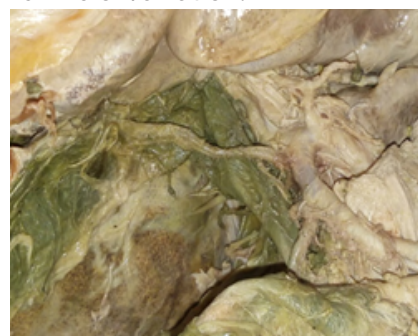

Fig.4: 1Cystic artery Passing Anterior To The CD
Not many studies had conducted regarding mutual connection between $\mathrm{CA}$ and $\mathrm{CD}$ individually.si it was difficult to compare our results with other studies.

\section{CONCLUSION:}

There was significant correlation found between length, breadth and variant of $\mathrm{CA}$ and $\mathrm{CD}$. Superficial and inferior relation of $C A$ in regards with $C D$ should keep in mind while dealing with Calot's triangle as ignorance may lead to hemorrhage. Thorough understanding is required to prevent post operative complications.

\section{REFERENCES:}

1. Dandekar UK, Dandekar KN. Anatomical study of cystic duct and its clinical correlation.MIJOANT.2019 Sept; 11(3): 62-65

2. Marniok B, Mikusek J, Wiewi.ra M, Yewski, Sosada K. Anatomical variations of cystic duct and artery in direct preparations Med Sci Monit.1999; 5(3): 395398.

3. Taimur M, Hasan $A$, Ullah $S$, Masood R, Imran M. Vascular variations in the Calot's triangle seen on laparoscopic cholecystectomy. Pak Armed Forces Med J.2011;61(4):16-20.

4. Turner MA, Fulcher AS, Gore RM, Levine MS. Textbook of Gastrointestinal Radiology in Gallbladder and Biliary Tract: Normal Anatomy and Examination Techniques.2nd ed. Philadelphia, PA: WB Saunders Co: 2000;2 1250-76.

5. Ramakrishna R, Tiwari S. Cystic Artery: An Anatomic Morphological Study and Its Clinical Significance.Natl J Clin Anat 2019;8:10-13.

6. Suzaki. M., Akaishi. S., Rikiyama. T., Rohman M. M. Matsuno. S. 'Laparoscopic cholecystectomy Calot's triangle, and variations in cystic arterial supply. Surg. Endos 2000, 14:141-144.

7. Doherty GM, Way LW. Biliary tract. In: Doherty GM. Current surgical diagnosisand treatment. 12th ed. Lang International edition McGraw Hill Companies, New York, 2006; 576-601

8. Gawali R. A 2014. A study on variations of origin and course of cystic artery and its relation to the Calot's triangle. International Journal of Medical and Pharmaceutical Sciences.;5(3):15-19.

9. Dundaraddy RY, Mahesh GM: Vascular variations in extrahepatic biliary system. BMJ.2012 Mar; 3:8-10. 